\title{
Towards a computer-based decision support system for aquaculture stakeholders in Greece in the context of climate change
}

\author{
Orestis Stavrakidis-Zachou* \\ Institute of Marine Biology, Biotechnology and Aquaculture, \\ Hellenic Centre for Marine Research, \\ Heraklion, 71500 Crete, Greece \\ and \\ Department of Biology, \\ University of Crete, \\ Heraklion, 71003, Crete, Greece \\ Email: ostavrak@hcmr.gr \\ *Corresponding author

\section{Nikos Papandroulakis} \\ Institute of Marine Biology, Biotechnology and Aquaculture, \\ Hellenic Centre for Marine Research, \\ Heraklion, 71500 Crete, Greece \\ Email:npap@hcmr.gr
}

\section{Astrid Sturm}

Brandenburg University of Technology Cottbus-Senftenberg, Erich-Weinert-Straße 1, 03046 Cottbus, Germany

Email: sturm@b-tu.de

\section{Panagiotis Anastasiadis}

Institute of Marine Biology, Biotechnology and Aquaculture, Hellenic Centre for Marine Research,

Heraklion, 71500 Crete, Greece

Email: casper@hcmr.gr

\section{Frank Wätzold}

Brandenburg University of Technology Cottbus-Senftenberg, Erich-Weinert-Straße 1, 03046 Cottbus, Germany

Email: waetzold@b-tu.de 


\title{
Konstadia Lika
}

\author{
Department of Biology, \\ University of Crete, \\ Heraklion, 71003, Crete, Greece \\ Email: lika@uoc.gr
}

\begin{abstract}
Climate change constitutes an increasing concern for aquaculture. The uncertainty surrounding the future implications of this phenomenon coupled with the financial importance of the sector necessitate the development of appropriate frameworks and tools that can support management decisions and ensure the sustainability of future aquaculture production. Facilitated by emerging information technologies, decision support systems (DSSs) are becoming increasingly popular in sectors of primary production and deal with various aspects of decision-making from the operational to the strategic level. In this paper we present ongoing work, in the frame of the EU-ClimeFish Project, towards the development of a computer-based DSS that simulates and visualises the impacts of different climate change scenarios on Greek aquaculture, including economic impacts. The description contains details on the structure, constituent models, and current status of implementation of the DSS. The applicability of the generated tool in decision-making is discussed and planning for further development is outlined.
\end{abstract}

Keywords: climate change; aquaculture; ClimeFish; decision support system; DSS; European sea bass; DEB model; economic model.

Reference to this paper should be made as follows: Stavrakidis-Zachou, O., Papandroulakis, N., Sturm, A., Anastasiadis, P., Wätzold, F. and Lika, K. (2018) 'Towards a computer-based decision support system for aquaculture stakeholders in Greece in the context of climate change', Int. J. Sustainable Agricultural Management and Informatics, Vol. 4, Nos. 3/4, pp.219-234.

Biographical notes: Orestis Stavrakidis-Zachou is a Research Biologist at the Hellenic Center for Marine Research and PhD candidate at the University of Crete. His area of interest is mathematical modelling of biological systems with focus on fish bioenergetics and particularly the effects of temperature on metabolism.

Nikos Papandroulakis is the Research Director at the Institute of Marine Biology, Biotechnology and Aquaculture of the Hellenic Center for Marine Research. He is interested in developing appropriate methodologies and automated management schemes for the Mediterranean aquaculture. He is also in the specific diversification with fast growing species.

Astrid Sturm is a computer scientist and works as Senior Researcher in the Chair of Environmental Economics at the Brandenburg University of Technology Cottbus-Senftenberg. Her main research focus is on algorithm design. In recent years, she worked in joint research groups with economist and ecologist to develop economic-ecologic models and implement them into software-based decision support systems.

Panagiotis Anastasiadis is a technician in the Institute of Marine Biology, Biotechnology and Aquaculture at the Hellenic Center for Marine Research. His area of interest is aquaculture technologies and processes, market studies, offshore technologies, and technology transfer. 
Frank Wätzold is a Professor of Environmental Economics at the Brandenburg University of Technology Cottbus-Senftenberg. His research focuses on economic analyses of biodiversity and ecosystem services as well as the development of software-based decision support systems.

Konstadia Lika is an Associate Professor of Biomathematics at the University of Crete. The general area of her research is mathematical modelling of biological systems with emphasis in fish bioenergetics, phytoplankton physiology, mixotrophy and ecophysiology.

This paper is a revised and expanded version of a paper entitled 'Towards a computer based ClimeFish DSS for aquaculture stakeholders in Greece' presented at 4th ICDSST - EWG-DSS Conference on Decision Support System Technology \& PROMETHEE Days 2018, Hellenic Center for Marine Research, Heraklion, Greece, 22-25 May 2018.

\section{Introduction}

Aquaculture is increasingly under pressure to meet the rising demand for animal protein spurred by global population increase. This has rendered aquaculture the fastest growing sector of the food industry. In Greece in particular, aquaculture products constitute a significant part of Greek exports with species such as the European sea bass (Dicentrarchus labrax) and gilthead sea bream (Sparus aurata) dominating the market. Greek production for those species represents more than $60 \%$ of the total EU production, while other species such as meagre (Argyrosomus regius) have also been introduced recently (FEAP, 2016).

At the same time, there is a rising concern that climate change will impact aquaculture in a number of ways (Brander et al., 2018). Due to peculiarities of the Mediterranean basin, such impacts can be intense and diverse in nature. The effects of climate-related drivers such as temperature and extreme events are rarely self-intuitive and, thus, give rise to both future threats and opportunities (Rosa et al., 2012). In this context, it is imperative that informed management incorporates the effects of climate change in a framework that ensures the sustainability and maximisation of production capacity for the sector in the coming decades. Under the Europe 2020 goals, the European Commission is financing research projects such as the ClimeFish Project. The project investigates the effects of climate change on the European seafood production while recognising the need to develop appropriate adaptation strategies in co-creation with stakeholders. One of the project's primary goals is to develop appropriate tools for some case studies of the participating countries (ClimeFish Project, 2018) that will facilitate decision-making. For the Greek aquaculture case study, this includes the development of a computer-based decision support system (DSS), which is described here.

A computer-based DSS can generally be regarded as an interactive, computer-based information system, specifically designed to support the decisions in relation to complex problems and improve decision-making and management planning. The main function of such a tool is to allow the end-user of the system, a decision maker, to compare the projected state with a desired state defined by a specific management objective. In the 
case of climate change, comparison with projections of possible future scenarios can point to appropriate management strategies for adaptation. However, the development of a DSS tackling climate change remains challenging. Not only because of the scientific uncertainty regarding future climate projections and the necessity for high-quality regionalised data but also due to the difficulty in maintaining a balance between loss of information and user's demands such as user-friendliness and interactivity (Wenkel et al., 2013).

Although computer-based DSSs are increasingly developed in multiple domains, literature is scarce with respect to aquaculture. Only a handful of such systems have been developed specifically for aquaculture over the last 25 years and, to our knowledge, none of them incorporates the impacts of climate change. However, the importance of existing environmental conditions on decisions regarding site selection has been investigated in several cases (Halide et al., 2009; Nobre et al., 2009; Stelzenmüller et al., 2017). Moreover, these systems generally consider a small number of species and focus on the effect of a single driver (or a limited number of them), thus, failing to capture the multifactorial nature of decision-making problems that are pertinent to the sector (Mathisen et al., 2016). However, it appears that there is an increased interest in the development of a new generation of support systems and other interactive model-based tools, mainly facilitated by achievements in the fields of computer science, climate modelling and data acquisition technologies (Wenkel et al., 2013). The relevance of a DSS in food production systems is highlighted by the large number of such tools developed over the last years (Cobo et al., 2018; Hermawan and Syafrani, 2015; Sturm et al., 2018; Wätzold et al., 2016) including tools focused on the effects of climate change on biodiversity, land use, and management of water resources (Kašpar et al., 2018; Pierleoni et al., 2014; Wenkel et al., 2013).

In this article, we describe the design and the progress achieved towards the development of the DSS for the Greek aquaculture case study as part of the ClimeFish Project. The DSS, which is aimed to outlive the duration of the project, simulates the effects of climate change on aquaculture production and selected associated economic indicators, and is based on a biological-economic modelling procedure (Wätzold et al., 2016). Considerable emphasis is given in developing a tool that is applicable at two levels of decision-making, operational and strategic. At an operational level, the DSS can be used to plan the activities of a farm for a given period while at a strategic level, it can influence decisions related to the long-term planning of aquaculture activity. Therefore, the DSS may prove useful for a wide range of users, in this case the aquaculture stakeholders. For this reason, by aquaculture stakeholders we here refer to farmers, administrators of zones of organised development of aquaculture (ZODA), administrators of producers' organisations, regional or national authorities, and other potential users that the DSS may be useful to. Another consideration here is the increase of the DSS relevance to the user, which has been recognised as a crucial element for the development of agricultural support systems (Antle et al., 2017; Capalbo et al., 2017). To address that, ClimeFish closely engages stakeholders by organising stakeholder meetings and presenting the software prototype with its background results several times during the project, so that stakeholder feedback can be incorporated into the final products.

The DSS described here constitutes the prototype developed utilising the preliminary results from the first round of biological simulations. It considers E. sea bass as the model species and has been presented to the stakeholders, incorporating their initial feedback. The description of the computer-based DSS contains details on its structure, its 
constituent models, and the current status of implementation. Concluding remarks highlight the applicability of the developed DSS and how it contributes to decision-making while discussing planning for further development.

\section{Description of the DSS}

\subsection{Structure}

The DSS simulates and visualises the effects of climate change on aquaculture production and associated economic indicators in Greece. These simulations use biological and economic information as input to explore how husbandry practices will alter the performance of different farms under future environmental scenarios. To do that, the basic structure of the DSS comprises of a coupled biological and economic model as well as a local database and a user interface. The basis of the analysis is a hypothetical fish farm, a modelling approach which is becoming increasingly popular in aquaculture (Cobo et al., 2018; Piedecausa et al., 2010). In this farm, the biological component relates to a cohort of fish being followed through the production process until harvested as a batch at sizes defined by the user. Respectively, the economic model translates changes in biology into changes in the economics of the farm. The economic data and information of the DSS contains mainly farm economic data and information but also information about the gross value added (GVA) on the level of the whole economy.

An important element of the structure, as well as an inherent limitation of the DSS, is that the biological simulations are pre-computed for a number of predefined scenarios and stored in the database. This is because the complexity of the biological model requires substantial computational time which renders it cumbersome for real time simulations and interactive communication with the user. On the contrary, all economic calculations take place in real time using the biological output retrieved from the database and input from the user, which is provided via the user interface. The interactive capacity of the tool lies in the ability of the user to create and compare alternative scenarios by selecting between the pre-calculated biological results and assigning economic input. The general structure of the DSS is shown in Figure 1.

Figure 1 General structure of the Greek aquaculture DSS

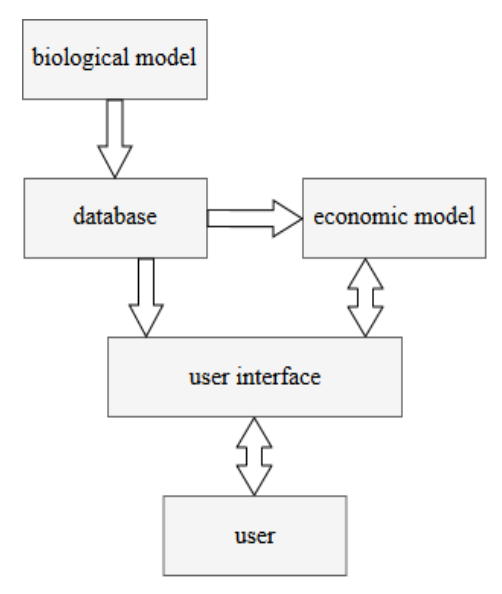


The DSS is flexible and can be adapted to accommodate emerging needs. The database contains general economic information as well as spatially specific data. Provided that the user can generate their own biological simulations, the new information can be uploaded in the database. Therefore, the capabilities of the DSS can be extended to include more fish species, regions, climate scenarios or simulation periods.

\subsection{Input parameters and data requirements}

The input parameters are defined by the biological and economic models.

For the biological model, input relates to the data used for the simulations. According to the objectives of the ClimeFish Project, two climate scenarios generated by the Intergovernmental Panel on Climate Change (IPCC) were considered, the Representative Concentration Pathways (RCPs) 4.5 and 8.5. Given the current status of anthropogenic carbon emissions, the former indicates the most probable future scenario and corresponds to a temperature increase of approximately $2.4^{\circ} \mathrm{C}$ by the end of the century compared to pre-industrial values. On the other hand, RCP 8.5 represents the worst case scenario, resulting respectively at a temperature increase of about $4.9^{\circ} \mathrm{C}$ (Rogelj et al., 2012). For the two climate scenarios, three time periods were considered, namely the periods 2015-2025, 2025-2035, and 2045-2055. These future periods reflect the average climate for 2020, 2030, and 2050, respectively, and represent short, mid and long-term projections.

Regarding the climate data used for the simulations, they were retrieved from the Norwegian earth system model (NorESM1-ME), a model of intermediate resolution. For the oceanic component, the vertical resolution is approximately $0.5^{\circ}$ while the horizontal resolution is $1.125^{\circ}$ along the equator and gradually decreases with latitude (Bentsen et al., 2013). For the study area this translates to grid cells of approximate $50 \times 100 \mathrm{~km}$. Due to the coarse resolution of the available data only three areas in Greece were selected for the first round of biological simulations, characterised as 'East', 'West' and 'South', with the central geographic coordinates of the corresponding cells being ' $38.72 \mathrm{~N}$, $25.81 \mathrm{E}$ ', '39.85N, 20.19E' and ' $35.70 \mathrm{~N}, 24.69 \mathrm{E}$ '. These areas were chosen because they cover representative parts of the geographical distribution of the aquaculture industry in Greece, thus allowing for inter-comparisons of climate effects at a regional scale, and because they coincide with the centres of three major administrative regions of Greece. More regions will be added at next stages of the project while the final simulations will utilise climate data at the higher resolution of $10 \times 10 \mathrm{~km}$.

The temporal scale for the biological data is a week and the simulation period for the hypothetical fish cohort three years. For this period, the user has access to the weekly values of the biological output so that they can inspect temporal changes in growth, biomass, and feed consumption throughout the production cycle, from seeding to harvest. Implicit assumptions here are the constant availability of juveniles, which in reality may be subject to seasonal changes, as well as the simultaneous harvesting of the whole cohort at a specific market size, which may also be untrue if market demand requires otherwise. In order to adjust production to seasonal changes in demand, as well as in order to optimise fish growth according to temperature throughout the year, farmers often implement multi-seeding schemes at various months. The software offers this option by running simulations for three potential seeding months, namely 'March', 'June', and 'August' for each one of the climate scenarios and simulation periods. Since seeding 
months for E. sea bass in Greece typically range from February to September, the chosen months cover the majority of that period.

With respect to the economic model, the various prices and costs must be assigned by the user in order to calculate the business economics of the farm. Input parameters include the feed price, market (sales) price, juvenile price, cost of labour, maintenance and other costs, cost of depreciation, and interest rate. The various costs and the interest rate can be included on a daily basis. To facilitate user orientation, information on the 'medium value of the last five years' for the various prices is provided.

\subsection{Biological model}

The biological model simulates the bioenergetics of a group of fish as a function of temperature and food availability for the duration of the whole production cycle. It comprises of a model that simulates the bioenergetics of an individual fish, the results of which are then extrapolated to the farm level by assigning population and farm characteristics. These characteristics may include inter-individual variability, size-dependent mortality, and farm size. The model for an individual fish is based on dynamic energy budget (DEB) theory for metabolic organisation (Kooijman, 2010) which allows for modelling the processes of feeding, digestion, maintenance, growth, maturation, reproduction and ageing.

For a detailed description of the modelling procedure, the parameterisation, and validation of the model for E. sea bass we refer to Stavrakidis-Zachou et al. (2019). Briefly, information on the life history, physiology and morphology of E. sea bass was obtained from both experimental work and published literature to estimate the parameters of the DEB model as described in Marques et al. (2019). Inter-individual variability was introduced by subdividing the population in cohorts that differ in the values of specific parameters. The validity of the model was subsequently assessed by comparing the model predictions with a number of independent production datasets, regarding growth and feed consumption, provided by farms. The farms were selected to cover representative areas of aquaculture activity in Greece in order to increase the robustness and applicability of the model for a wide spatial scale.

The output of the model includes variables such as the mean individual weight-attime, the number of fish, the total biomass, the specific growth rate (SGR), the cumulative feed consumption and the feed conversion ratio (FCR). SGR is calculated as the percentage of weight gain on a daily basis and FCR as the feed given over the weight gained.

\subsection{Economic model}

The economic model is implemented into the software as an add-on to the biological model and is provided by Syntesa (2018), a partner of the ClimeFish consortium with expertise in economics and in particular, socio-economic assessment and cost benefit analysis. The collection and calculation of economic data and information for the model is currently developed in close collaboration between HCMR, the Greek aquaculture industry and Syntesa.

The core of the model is the business economics section. It uses the output of the biological model and the user input to simulate the economics of a single farm, by 
focusing on the calculation of the main farm costs and derivation of the profit. These results can then be scaled up to include additional farms within a region. All prices used in the calculation of costs and profit are user defined thus allowing flexibility for the user to test a wide range of economic scenarios. The most important operational costs in finfish aquaculture are related to feed and feeding (Baki and Yücel, 2017). These are commonly followed by labour which includes expenses for wages and additional costs of hiring personnel. The initial capital for obtaining seed (juveniles) can also be substantial while other costs such as those relating to maintenance or depreciation (cost of depreciations of the equipment, buildings, storage and vessels) can also increase the total production costs (Koçak and Tathildi, 2004). Moreover, it appears that these costs are affected by the farm size. For instance, the relative costs for labour or transport can be substantially lower for large farms compared to small ones (Engle, 2010). Finally, debt seems to constitute an important factor in aquaculture due to the relative long production cycle of the farmed species as well as the loans taken to finance the expensive specialised infrastructure (Engle, 2010). The assumption used here is that during the production period costs have to be financed by loans and the debt keeps on accumulating until the fish is harvested and sold. The main functions for calculating the economic variables mentioned above are provided in Appendix.

\section{Implementation of the DSS}

\subsection{User interface and simulation}

A successful DSS must be accessible to non-technical specialists and provide information in a simplified and understandable way (Cobo et al., 2018). Therefore, the design of the user interface is a vital component of the system. The user interface developed here uses both numerical and graphical elements to comprehensively present the outputs and its current appearance is shown in Figure 2. It comprises of a main window, which offers a series of user defined preferences, and a number of secondary windows (indicated with dark blue colour) that contain detailed descriptions of the results.

The operation of the software is performed in two phases. First, the user selects the characteristics of the farm and the rearing conditions for the fish from the predefined options, and the biological output is retrieved from the database. These choices relate to the climate scenario, the simulation period, the farm size and location, and the seeding scheme (month and seeding size). At this stage, the user defines the fish size at which the batch will be harvested. Since E. sea bass prices are based on commercial classes, this allows flexibility in the marketing plans the user can investigate. The information that the user receives is the time and the cumulative feed required to reach that particular market size, the total biomass produced for each of the three available seeding months, the SGR, and the FCR. For illustrative purposes, this is also available in the form of graphs where the user can follow the evolution of those variables in time for the duration of the on-growing period (Figure 3).

In the second step, the biological output is used as input for the economic simulation. Based on the values for the various prices and costs the user assigns at this step, the model calculates the business economics of the farm. Total profit and the associated costs are provided both numerically, as the sum of the batch harvests for the chosen seeding scheme, or graphically for the different seeding months. Another option that the software 
offers, is the use of an optimisation module. This aims at identifying the optimal market size or seeding scheme for specific production goals. In the first case, the software takes into account the chosen seeding scheme and estimates the market size that would maximise profit. In the second case, the user can assign a target biomass and the software recommends the most efficient seeding scheme, based on the market size that has already been decided.

Figure 2 Screenshot of the main user interface of the Greek aquaculture DSS (see online version for colours)

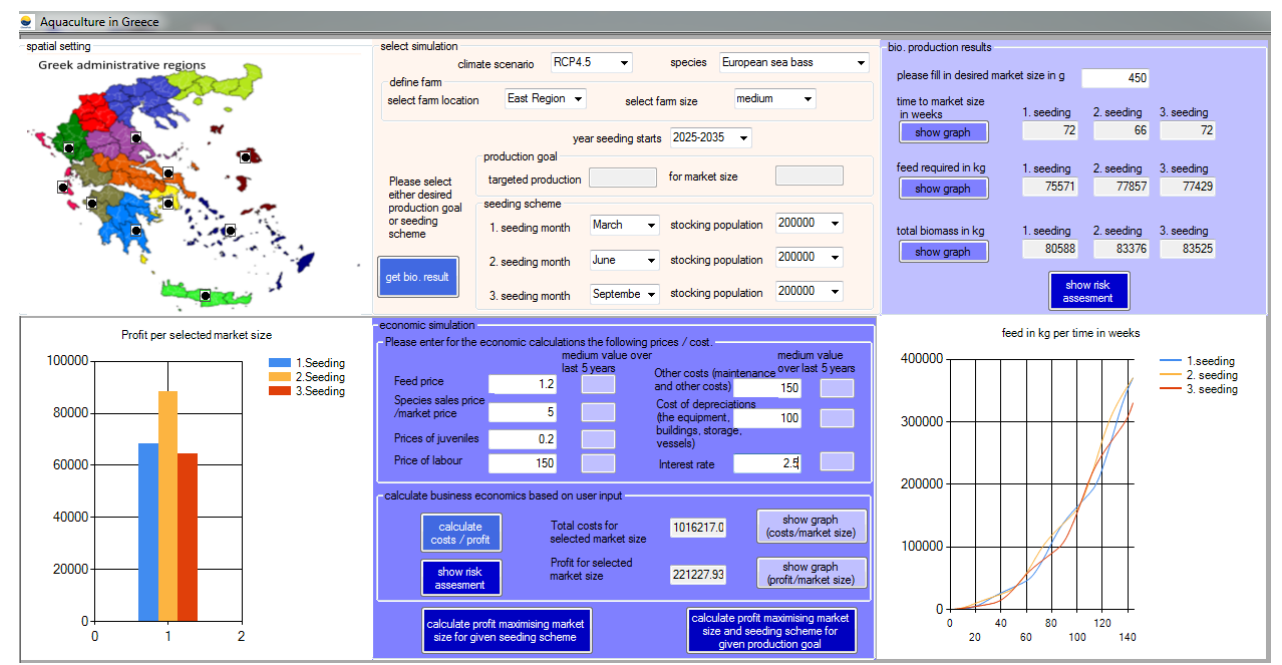

Figure 3 Examples of biological output (see online version for colours)
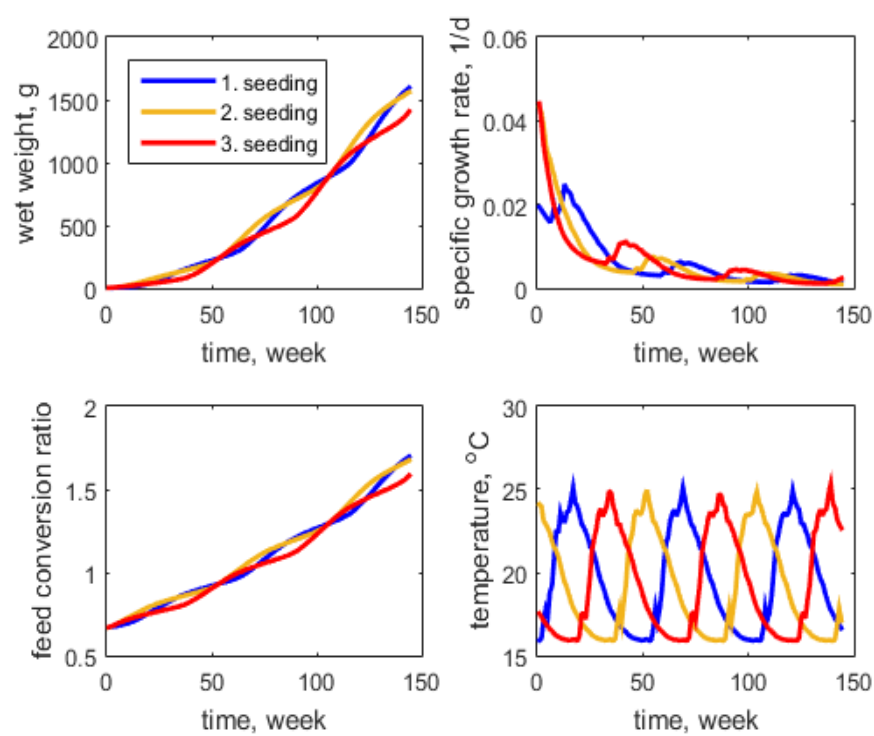

Note: Weight, FCR, SGR and temperature as a function of time for three seeding schemes. 


\subsection{Technical implementation}

The Greek ClimeFish DSS is developed in C\# using open source software components and it is available for Microsoft Windows systems. It operates in connection with a local MySQL database, where all model parameters and supporting data are stored. The database uses a freely available version of MySQL Community Server release 8.0.12 (MySQL, 2018) which supports all the basic database structures and functionality needed for the project's purpose. The database structure is shown in Figure 4. To run the executable, the user is required to first install the MySQL on their computer which can be done using open source software (XAMPP, 2018).

Figure 4 Structure of the MySQL database (see online version for colours)

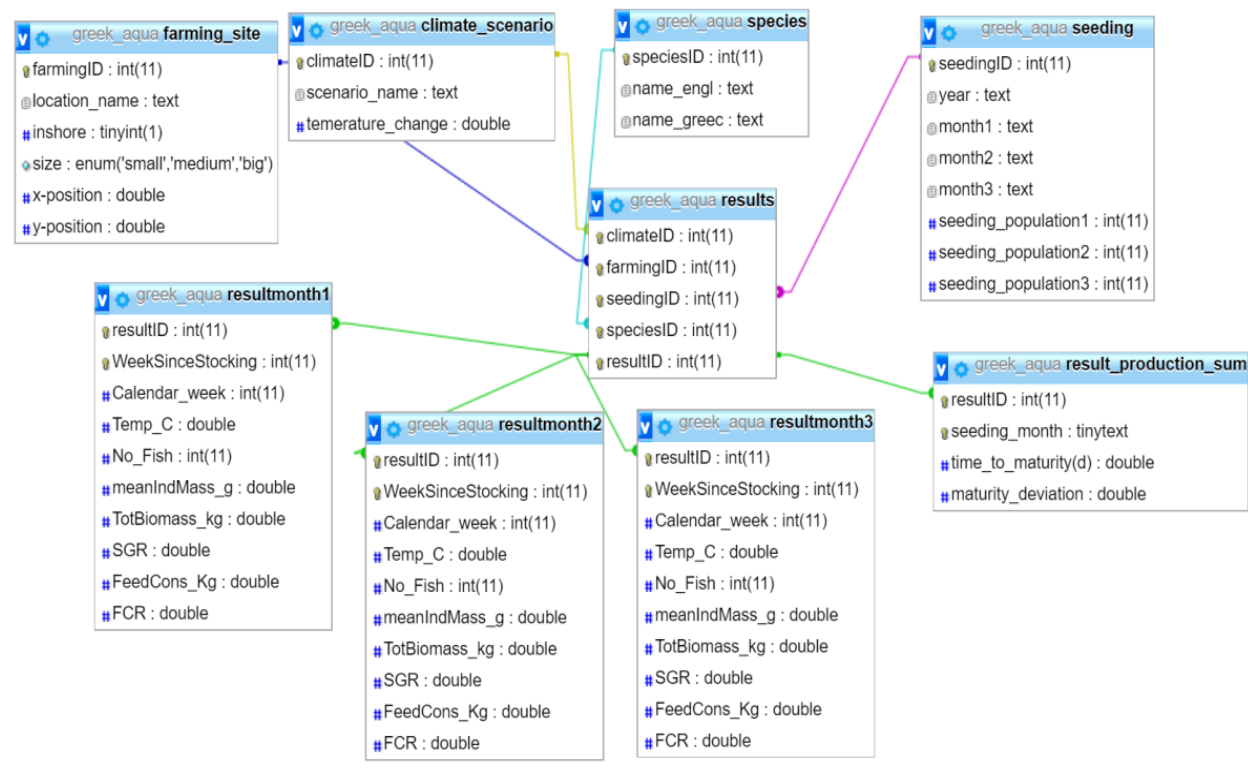

Being a prototype, the version is at present available only for scientific work within the ClimeFish consortium including the stakeholders involved in the development and validation of the tool. Upon completion, the software, as well as its source code, will be available free of charge on the ClimeFish webpage among the rest of the tools generated during the project.

\subsection{Stakeholder interaction}

The ClimeFish Project actively engages stakeholders at various stages of its development in order to ensure that the generated tools are not only scientifically appropriate but also pertinent to the sector from an economic point of view. It is vital that stakeholders are involved as early as possible in the co-creation process of the DSS development in order to increase the relevance of the tool for the users (McIntosh et al., 2011).

For that reason, a stakeholder kick-off meeting was carried out in Vigo, Spain, early in the project in 2016. Stakeholder views on the potential threats of climate change on 
aquaculture production as well as the specific challenges the sector faces were discussed, and the features, capabilities, and limitations of the DSS to be developed were outlined. Once the first biological simulations were completed, a second stakeholder meeting, which involved representatives from both the industry and the administration, was arranged in April 2018 in Athens, Greece. In line with recommendations from other authors (Sturm et al., 2018), effort was given not only in achieving a high overlap between the participants of the two meeting but also in engaging stakeholders with relatively long time horizons (longer than the duration of the project). During the meeting, the current features of the DSS and the preliminary biological results were presented. Attention was given in discussing the strengths and constraints of the software to avoid misinterpretation of the function and capabilities of the tool. Since the perception of users regarding the use of a DSS ranges from sceptical to those fully entrusting decision-making to the software, it is imperative that emphasis is given in presenting the tool as an aid to decision-making that cannot nor should replace human critical thinking from the decision-making process (Sturm et al., 2018).

The range of questions the DSS may provide answers to is wide. It includes, but is not limited to, the optimal stocking time for a batch of fish, the optimal harvest size, the role of farm size on its economics, and the suitability of geographical locations for fish farms in Greece. This in turn allows for application of the tool to decisions of both operational and strategic importance. The calculation of daily feed rations or the timely planning of harvesting at specific market sizes are examples of operational decisions that the DSS can support. On the other hand, the selection of locations for new farm installations, the selection of optimum harvest size for certain economic and climate scenarios or the investment in technologies and marketing plans that minimise certain costs and increase profitability are examples of the latter. Stakeholders showed interest in these capabilities of the DSS and particularly in the ability to investigate and visualise climate and husbandry 'what-if' scenarios and their effects on production. They provided insightful feedback on the work presented which included recommendations on output visualisation as well as on the inclusion or exclusion of certain features of the DSS.

\section{Conclusions}

The complexity of aquaculture activity requires elements of economic, technical, biological, environmental and legislative nature to be considered in the decision-making process. Therefore, informed decisions rely on the development of appropriate frameworks that use robust and reliable tools to predict the impact of the factors affecting the industry. Climate change is yet one more of these factors and the necessity to address the imminent, but to a large extent uncertain, implications of the phenomenon on aquaculture has been recognised. Although the majority of DSS developed in aquaculture have so far focused on the effect of a limited number of factors on farm operation, production or profitability, there is an increasing trend for the development of multi-criteria approaches and tools that are more effective at supporting decision-making (Vergara-Solana et al., 2018). Here, we presented ongoing work towards the development of a DSS for aquaculture stakeholders in Greece that simulates the effects of climate change on aquaculture by incorporating environmental, economic and husbandry parameters. 
Taking into consideration the stakeholder feedback and the specifications outlined within the project, further steps will be taken towards the development of the DSS until the next and final stakeholder meeting in 2019. Future development will address existing uncertainties by fine-tuning the biological and economic models and increase the robustness of the biological forecasting while adding new functionalities. The spatial resolution of the simulations will increase according to the availability of climate data while more regions will be added in the analysis.

Furthermore, a risk assessment of the potential threats and opportunities that arise from climate change will be incorporated into the software. The purpose is to provide additional information for processes that cannot be explicitly modelled and by doing so to allow users to evaluate the output of the DSS and assess potential management options in a more holistic context. Risk will be assessed as a function of probability of various climate events and the potential impacts or consequences that they may have. The methodology is currently under construction and the perception of stakeholders on the severity and likelihood of potential climate change impacts is already being evaluated. A further step, tied to the risk assessment, is the inclusion of an early warning system to the software. For this, specific monitoring values for biological and economic parameters that may indicate tipping points on the viability of the farm need to be defined. The results of this system will be visualised as explicit warnings for scenarios outcomes that are not satisfactory, or put in danger or risk the rearing viability.

An additional modification will be the inclusion of the effect of extreme events such as storms and heat-waves on production and profitability, which was recognised as an important concern by the stakeholders. Such events have significant cost for aquaculture by causing, among others, mortalities, diseases, growth irregularities, obligatory fasting, reduced access to the farm and damage to the facilities (Ruby and Ahilan, 2018). Future work will aim to incorporate the frequency and intensity of extreme events into the model. Furthermore, future simulations will also differentiate between offshore and inshore farms due to the interest the former is gaining in aquaculture and the notable differences in environmental exposure these two types of farming are subjected to (Gentry et al., 2017). Finally, E. sea bass is currently the only available species in the database but a second species, meagre (Argyrosomus regius), will also be included in the final product.

In conclusion, the ClimeFish DSS for aquaculture stakeholders in Greece presented here handles various aspects of decision-making which can be quantitative or qualitative and be applied at operational and strategic levels of decision-making. In the context of climate change, the ability to support strategic decisions is particularly important both for developing management plans and mitigation strategies to address its adverse impacts and for efficiently exploiting the emerging opportunities. Therefore, the computer-based DSS, with its pending modifications, may prove a useful tool for analysing future changes at scales that range from individual farms up to national legislation. 


\section{References}

Antle, J.M., Jones, J.W. and Rosenzweig, C. (2017) 'Next generation agricultural system data, models and knowledge products: introduction', Agricultural Systems, Vol. 155, Special issue, pp.186-190.

Baki, B. and Yücel, S. (2017) 'Feed cost/production income analysis of seabass (Dicentrarchus labrax) aquaculture', International Journal of Ecosystems and Ecology Sciences, Vol. 7, No. 4, pp.859-864.

Bentsen, M., Bethke, I., Debernard, J.B., Iversen, T., Kirkevåg, A., Seland, Ø., Drange, H., Roelandt, C., Seierstad, I.A., Hoose, C. and Kristjánsson, J.E. (2013) 'The Norwegian earth system model, NorESM1-M - part 1: description and basic evaluation of the physical climate', Geoscientific Model Development, Vol. 6, No. 3, pp.687-720.

Brander, K.M., Cochrane, K., Barange, M. and Soto, D. (2018) 'Climate change implications for fisheries and aquaculture', in Phillips, B. et al. (Eds.): Climate Change Impacts on Fisheries and Aquaculture: A Global Analysis, pp.45-63, Wiley-Blackwell, West Sussex, United Kingdom.

Capalbo, S.M., Antle, J.M. and Seavert, C. (2017) 'Next generation data systems and knowledge products to support agricultural producers and science-based policy decision making', Agricultural Systems, Vol. 155, Special issue, pp.191-199.

ClimeFish Project (2018) [online] http://www.climefish.eu/aims-and-goals (accessed 15 December 2018).

Cobo, A., Llorente, I., Luna, L. and Luna, M. (2018) 'A decision support system for fish farming using particle swarm optimization', Computers and Electronics in Agriculture, in press, DOI: 10.1016/j.compag.2018.03.036.

Engle, C.R. (2010) Aquaculture Economics and Financing: Management and Analysis, Blackwell Scientific, Ames, Iowa, USA.

Federation of European Aquaculture Producers (FEAP) (2016) European Aquaculture Production Report 2007-2015, prepared by the FEAP Secretariat [online] http://www.aquamedia.org/shortcut.asp?FILE=1487 (accessed July 2016).

Gentry, R.R., Lester, S.E., Kappel, C.V., White, C., Bell, T.W., Stevens, J. and Gaines, S.D. (2017) 'Offshore aquaculture: spatial planning principles for sustainable development', Ecology and Evolution, Vol. 7, No. 2, pp.733-743.

Halide, H., Stigebrandt, A., Rehbein, M. and McKinnon, A.D. (2009) 'Developing a decision support system for sustainable cage aquaculture', Environmental Modelling and Software, Vol. 24, No. 6, pp.694-702.

Hermawan, S. and Syafrani (2015) 'An integrated decision support system for the management of sustainable mariculture in Indonesia', Advances in Environmental Biology, Vol. 9, No. 7, pp.21-27.

Kašpar, J., Bettinger, P., Vacik, H., Marušák, R. and Garcia-Goncalo, J. (2018) 'Decision support approaches in adaptive forest management', Forests, Vol. 9, DOI: 10.3390/f9040215.

Koçak, Ö. and Tathildi, F. (2004) 'Cost analysis in gilthead sea bream (Sparus aurata Linnaeus, 1758) and sea bass (Dicentrarchus labrax Linnaeus, 1758) production in Mila district-Muğla Province, Turkey', Turkish Journal of Fisheries and Aquatic Sciences, Vol. 4, No. 1, pp.33-38.

Kooijman, S.A.L.M. (2010) Dynamic Energy Budget Theory for Metabolic Organisation, 3rd ed., Cambridge University Press, UK.

Marques, G.M., Lika, K., Augustine, S., Pecquerie, L. and Kooijman, S.A.L.M. (2019) 'Fitting multiple models to multiple data sets', Journal of Sea Research, Vol. 143, Special Issue, pp.48-56, DOI: 10.1016/j.seares.2018.07.004.

Mathisen, B.M., Haro, P., Hanssen, B., Björk, S. and Walderhaug, S. (2016) Decision Support Systems in Fisheries and Aquaculture: A Systematic Review, ArXiv e-prints [online] https://arxiv.org/abs/1611.08374 (accessed July 2018). 
McIntosh, B.S., Ascough J.C., Twery, M., Chew, J., Elmahdi, A., Haase, D., Harou, J.J., Hepting, D., Cuddy, S., Jakeman, A.J, Chen, J., Kassahun, A., Lautenbach, S., Matthews, K., Merritt, W., Quinn, N.W.T., Rodriquez-Roda, I., Sieber, S., Stavenga, M., Sulis, A., Ticehurst, J., Volk, M., Wrobel, M., van Delden, H., El-Sawah, S., Rizzoli, A.E. and Voinov, A.A. (2011) 'Environmental decision support systems (EDSS) development - challenges and best practices', Environmental Modelling and Software, Vol. 26, No. 12, pp.1389-1402.

MySQL (2018) [online] https://www.mysql.com/ (accessed 15 December 2018).

Nobre, A.M., Musango, J.K., de Wit, M.P. and Ferreira, J.G. (2009) 'A dynamic ecologicaleconomic modelling approach for aquaculture management', Ecological Economics, Vol. 68, No. 12, pp.3007-3017.

Piedecausa, M.A., Aguado-Giménez, F., Cerezo-Valverde, J., Hernández-Llorente, M.D. and García-García, B. (2010) 'Simulating the temporal pattern of waste production in farmed gilthead seabream (Sparus aurata), European sea bass (Dicentrarchus labrax) and Atlantic bluefin tuna (Thunnus thynnus)', Ecological Modelling, Vol. 221, No. 4, pp.634-640.

Pierleoni, A., Camici, S., Brocca, L., Moramarco, T. and Casadei, S. (2014) 'Climate change and decision support systems for water resource management', Procedia Engineering, Vol. 70, No. 1, pp.1324-1333.

Rogelj, J., Meinshausen, M. and Knutti, R. (2012) 'Global warming under old and new scenarios using IPCC climate sensitivity range estimates', Nature Climate Change, Vol. 22, No. 4, pp.248-253.

Rosa, R., Marques, A. and Nunes, M.L. (2012) 'Impact of climate change in Mediterranean aquaculture', Reviews in Aquaculture, Vol. 4, No. 3, pp.163-177.

Ruby, P. and Ahilan, B. (2018) 'An overview of climate change impact in fisheries and aquaculture', Climate Change, Vol. 4, No. 13, pp.87-94.

Stavrakidis-Zachou, O., Papandroulakis, N. and Lika, K. (2019) 'A DEB model for European sea bass (Dicentrarchus labrax): parameterisation and application in aquaculture', Journal of Sea Research, Vol. 143, Special Issue, pp.262-271, DOI: 10.1016/j.seares.2018.05.008.

Stelzenmüller, V., Gimpel, A., Gopnik, M. and Gee, K. (2017) 'Aquaculture site-selection and marine spatial planning: the roles of GIS-based tools and models', in Buck, B. et al. (Eds.): Aquaculture Perspective of Multi-Use Sites in the Open Ocean, pp.131-148, Springer, New York, USA.

Sturm, A., Drechsler, M., Johst, K., Mewes, M. and Wätzold, F. (2018) 'DSS-Ecopay - a decision support software for designing ecologically effective and cost effective agri-environment schemes to conserve endangered grassland biodiversity', Agricultural Systems, Vol. 161, No. 1, pp.113-116.

Syntesa (2018) [online] http://www.syntesa.fo/ (accessed 15 December 2018).

Vergara-Solana, F., Araneda, M. and Ponce-Díaz, G. (2018) 'Opportunities for strengthening aquaculture industry through multicriteria decision-making', Reviews in Aquaculture, DOI: 10.1111/raq.12228.

Wätzold, F., Drechsler, M., Johst, K., Mewes, M. and Sturm, A. (2016) 'A novel, spatiotemporally explicit ecological-economic modelling procedure for the design of cost effective agri-environment schemes to conserve biodiversity', American Journal of Agricultural Economics, Vol. 98, No. 2, pp.489-512.

Wenkel, K.O., Berg, M., Mirschel, W., Wieland, R., Nendel, C. and Köstner, B. (2013) 'LandCaRe DSS - an interactive decision support system for climate change impact assessment and the analysis of potential agricultural land use adaptation strategies', Journal of Environmental Management, Vol. 127, No. 1, pp.168-183.

XAMPP (2018) [online] https://www.apachefriends.org/index.html (accessed 15 December 2018). 


\section{Appendix}

The main functions of the economic model

All prices are user defined.

The cost of feed $(€)$ is calculated as:

$$
\text { Feed costs }=\text { Feed consumption } \times \text { Price }_{\text {feed }}
$$

where Feed consumption (output of the biological model), is the quantity of feed $(\mathrm{kg})$ consumed during the production cycle, and Price $_{\text {feed }}$ the feed price $(€ / \mathrm{kg})$.

The cost of obtaining seed $(€)$ is calculated as:

$$
\text { Juveniles costs }=\text { Number of juveniles } \times \text { Price }_{\text {juveniles }}
$$

where Number of juveniles is the number of individuals purchased and Price $_{\text {juveniles }}$ their price ( $€$ /individual). Both are user inputs.

Cost of labour $(€)$ is calculated as:

$$
\text { Labour costs }=\text { Production days } \times \text { Price }_{\text {labour }} \times \text { Farm size factor }
$$

where Production days (output of the biological model) is the number of days from stocking to harvest and Price $_{\text {labour }}$ the total daily cost ( $€ /$ day) for the labour required to attend the batch. The Farm size factor is a variable that relates farm size to the various costs. This correction accounts for the fact that there exists a decreasing marginal cost related to the farm size.

Other costs $(€)$ are calculated as:

$$
\text { Other costs }=\text { Production days } \times \text { Cost }_{\text {other }} \times \text { Farm size factor }
$$

where Cost $_{\text {other }}$ is the daily cost ( $€ /$ day) related to maintenance and other operational costs not accounted above. Production days and Farm size factor as in equation (3).

Depreciations costs $(€)$ are calculated as:

Depreciations costs $=$ Production days $\times$ Costs $_{\text {depreciation }} \times$ Farm size factor

where Costs $_{\text {depreciation }}$ is the daily cost of depreciations ( $€ /$ day) for the equipment, buildings, storage, and vessels. Production days and Farm size factor as in equation (3).

The accumulated debt $(€)$ is calculated as:

$$
\begin{aligned}
\text { Accumulated debt }_{t} & =\text { Accumulated debt }_{t-1}+\text { Feed cost } s_{t} \\
& + \text { Juveniles cost }_{t}+\text { Labour cost }_{t}+\text { Other costs } t_{t} \\
& + \text { Price }_{\text {interest rate }} \times \text { Accumulated debt }_{t-1}
\end{aligned}
$$

where $t$ denotes the current production period and $t-1$ denotes the previous period. Price $_{\text {interest }}$ rate is the daily interest rate (\%/day) imposed by the banks while the term Price $_{\text {interest rate }} \times$ Accumulated debt refers to the interest $(€)$ added to the existing debt. 
Total costs $(€)$ are calculated as the sum of all costs:

Total costs $=$ Feed costs + Juveniles costs + Labour costs + Other costs

+ Depreciations costs + Interest

Income $(€)$ is calculated as:

Income $=$ Production $\times$ Price $_{\text {sales }}$

where Production (output of the biological model) is the fish biomass harvested (kg) and Price $_{\text {sales }}$ the Ex Works (sellers price before transport and other costs are added) sales price $(€ / \mathrm{kg})$.

Based on the above, the Profit $(€)$ function is:

$$
\text { Profit }=\text { Income }- \text { Total costs }
$$

Finally, the GVA $(€)$ is calculated as the multiplication of the unit farm economics with the number of farms:

$$
\begin{aligned}
G V A_{\text {Aquaculture }}= & \text { Number of farms } \times(\text { Income }- \text { Feed costs }- \text { Juveniles costs } \\
& - \text { Other costs })
\end{aligned}
$$

